\title{
Multigene Testing in Localized Prostate Cancer
}

\author{
Presented by Ashley E. Ross, MD, PhD
}

\begin{abstract}
Currently, there are several commercially available multigene tests for risk stratification in prostate cancer. These tests have been validated retrospectively; however, prospective studies are needed to fully establish their clinical roles. In some cases, molecular studies may add value, and updated NCCN Guidelines recommend "consideration" of molecular tests under certain circumstances, such as to help ascertain the likelihood of death from conservative management, of biochemical progression after radical prostatectomy or external-beam therapy, and of developing metastasis after radical prostatectomy or salvage radiotherapy.
\end{abstract}

J Nat/ Compr Canc Netw 2016;14(5.5):659-662

The availability of prognostic molecular tests for localized prostate cancer opens a range of possibilities, and at the same time is confusing for providers and patients. What are the differences among these tests? Are these new tests clinically useful? Will they change management beyond existing guidelines? Should they be ordered routinely or under specific circumstances?

Currently, these questions cannot be answered, and although all but one of the multigene tests have been validated retrospectively, prospective studies are needed to establish the role of multigene testing. Additionally, head-to-head comparisons of available molecular tests are warranted but probably will not be performed because of competing marketing forces, explained Ashley E. Ross, MD, PhD, of The Sidney Kimmel Comprehensive Cancer Center at Johns Hopkins.

Dr. Ross, Assistant Professor of Urology, Oncology, and Pathology, reviewed the evidence supporting the validity of currently available molecular prognostic tests for localized prostate cancer. He noted that the

Presented by Ashley E. Ross, MD, PhD, Departments of Urology, Oncology, and Pathology, The Sidney Kimmel Comprehensive Cancer Center at Johns Hopkins, Johns Hopkins School of Medicine, Baltimore, Maryland.

Dr. Ross has disclosed that he receives grant/research support from Merck \& Co., Inc., Novartis Pharmaceuticals Corporation, Metamark Genetics, Inc., and GenomeDX Biosciences; he also receives consulting fees, honoraria, and equity interest/stock options from GenomeDX Biosciences.

Correspondence: Ashley E. Ross, MD, PhD, The Sidney Kimmel Comprehensive Cancer Center at Johns Hopkins, 725 North Wolfe Street, Baltimore, MD 21205. E-mail: aross2@jhmi.edu field is moving toward developing predictive (vs prognostic) tests indicating whether a patient will respond to a particular therapy, and he said that predictive tests will undoubtedly be more clinically useful.

"Last year, NCCN incorporated molecular testing into the NCCN Guidelines for Prostate Cancer for the first time. This was not a hard recommendation, and the wording said to 'consider' available tests under certain circumstances," Dr. Ross explained. The NCCN Guidelines recommendation states: "Men with clinically localized disease may consider the use of tumor-based molecular assays. Retrospective case cohort studies have shown that molecular assays performed on biopsy or prostatectomy specimens provide prognostic information independent of NCCN risk groups. These include, but are not limited to, likelihood of death with conservative management, likelihood of biochemical progression after radical prostatectomy or external-beam therapy, and likelihood of developing metastasis after radical prostatectomy or salvage radiotherapy."

"Localized prostate cancer is characterized by extraordinary genomic complexity, with various copy number alterations-including deletions and amplifications-chromosomal rearrangements, and, to a lesser extent, point mutations," Dr. Ross said. "The hope is that molecular tests can aid in treatment selection and in deciding which patients need treatment intensification." Available molecular tests for localized prostate cancer are summarized in Table 1. 
Ross

Cell cycle abnormalities are common in localized prostate cancer, and Prolaris (Myriad Genetics, Inc., Salt Lake City, UT) and immunohistochemistry from $\mathrm{Ki}-67$ are specific to the cell cycle, whereas PTEN, ProMark (Metamark Genetics, Inc., Cambridge, MA), Decipher (GenomeDx Biosciences, San Diego, CA), and Oncotype DX (Genomic Health, Inc., Redwood City, CA) tests are based on molecular features of prostate cancer. PTEN and Ki67 assays cost approximately $\$ 100$ each and are not commercially marketed. ProMark, Decipher, Prolaris, and Oncotype DX tests cost approximately $\$ 3,000$ to $\$ 4,000$ per test.

PTEN loss is an early and important event in prostate cancer, and it can be detected in 15\% to $40 \%$ of primary cancers and in approximately $50 \%$ of metastatic cancers. "Loss of PTEN is correlated with stage and grade [of prostate cancer]," he said. "Loss of PTEN puts low-risk disease into a high-risk category, whereas in high-risk disease, loss of PTEN does not have much significance." $\mathrm{Ki}-67$, assayed by immunohistochemistry, has independent prognostic significance, Dr. Ross noted, but is not readily quantitative and may not robustly capture the proliferative status of cells.

Prolaris, a quantitative polymerase chain reaction (PCR) test based on 31 cell cycle genes normalized to 15 housekeeping genes, has use in all risk categories of prostate cancer and provides "added prognostic information," Dr. Ross said. In one study, an increased Prolaris cell cycle proliferation (CCP) score correlated with an increase in prostate cancer biochemical recurrence after radical prostatectomy and prostate cancer death in patients managed with watchful waiting. ${ }^{1}$ These findings were validated in a second study in which an increased CCP score resulted in decreased survival after radical prostatectomy in patients at low, intermediate, and high risk. ${ }^{2}$

Two studies validated Prolaris in needle biopsy cohorts after radical prostatectomy ${ }^{3}$ and after radiation. ${ }^{4}$ After prostatectomy, an increased CCP score predicted biochemical recurrence and increased the risk of metastasis (hazard ratio [HR], 1.5 and 4.2, respectively) per unit increase in score on multivariate analysis. Further, in a group of men conservatively managed undergoing needle biopsy in the Prostate Cancer Transatlantic Consortium, the HR for death per unit of CCP increase was approximately $2 .{ }^{5}$ Therefore, Cuzick et $\mathrm{al}^{5}$ suggested that the CCP score can identify men who can be managed conservatively.

\section{Multiplex Testing}

Oncotype DX for prostate cancer generates a genomic score based on quantitative reverse transcription PCR of 12 genes and 5 housekeeping genes. Each 20-point increase in Genomic Prostate Score (GPS) is equivalent to a 2 -fold risk of greater than Gleason $4+3$ or pT3 disease at radical prostatectomy. Oncotype DX is intended to evaluate biopsies in men with low- or low-intermediate-risk disease managed on active surveillance. The performance of Oncotype DX has not yet been reported in active surveillance cohorts but has been reported in men undergoing prostatectomy. In a meta-analysis of 732 patients from 2 studies, the GPS score added predictive value to the CAPRA-S (the Cancer of the Prostate Risk Assessment Postsurgical) score in predicting the likelihood of unfavorable pathology on prostatectomy across different NCCN subgroups. ${ }^{6}$

ProMark is a multiplex proteomics assay also designed to evaluate biopsy specimens and predict unfavorable pathology at prostatectomy. The test has been studied in biopsies from men undergoing prostatectomy, but it has not yet been validated or tested in a longitudinal cohort.

The Decipher test was designed for use in prostatectomy tissue and biopsy specimens, and is based on 22 genomic markers selected for their ability to predict rapid development of metastasis after radical prostatectomy. Decipher has been validated in 3 different studies: a Mayo Clinic study ${ }^{8}$ of 219 men with high-risk prostate cancer, a Johns Hopkins study ${ }^{9}$ of 260 intermediate- and high-risk men, and a Cleveland Clinic study ${ }^{10}$ of 169 men. In all 3 cohorts, Decipher was an independent predictor of metastatic progression following prostatectomy.

In addition to the ability of Decipher to predict metastatic progression after treatment, it also has been shown to predict prostate cancer-specific mortality, with scores greater than 0.6 having an 11 times higher risk of prostate cancer-specific mortality compared with lower Decipher scores $(<0.4) .{ }^{11}$ Beyond predicting which men may have aggressive prostate cancer, "Decipher may be able to better predict which men don't need salvage therapy after biochemical recurrence following radical prostatectomy," Dr. Ross said. When compared with the Briganti nomogram and CAPRA-S in the post-radical prostatectomy settings of adjuvant and salvage radiation, the Decipher score led to the reclassification of 
Multigene Testing in Prostate Cancer

\begin{tabular}{|c|c|c|c|}
\hline Test & Platform & $\begin{array}{l}\text { Populations } \\
\text { Studied }\end{array}$ & $\begin{array}{l}\text { Outcome Reported } \\
\text { (Test Independently Predicts) }\end{array}$ \\
\hline \multirow[t]{5}{*}{ Decipher } & \multirow{5}{*}{$\begin{array}{l}\text { Whole-transcriptome } 1.4 \mathrm{M} \\
\text { RNA expression ( } 44,000 \text { genes) } \\
\text { oligonucleotide microarray } \\
\text { optimized for FFPE tissue }\end{array}$} & \multirow{2}{*}{$\begin{array}{l}\text { Post RP, adverse pathology/high-risk } \\
\text { features }\end{array}$} & Metastasis \\
\hline & & & $\begin{array}{l}\text { Prostate cancer-specific } \\
\text { mortality }\end{array}$ \\
\hline & & \multirow[t]{2}{*}{ Post RP, biochemical recurrence } & Metastasis \\
\hline & & & Biochemical failure \\
\hline & & $\begin{array}{l}\text { Post } \mathrm{RP} \text {, adjuvant or salvage } \\
\text { radiotherapy }\end{array}$ & Metastasis \\
\hline \multirow[t]{2}{*}{ Ki-67 } & \multirow[t]{2}{*}{$\mathrm{IHC}$} & $\begin{array}{l}\text { Biopsy, intermediate- to high-risk } \\
\text { treated with RT }\end{array}$ & Metastasis \\
\hline & & $\begin{array}{l}\text { Biopsy, conservatively managed } \\
\text { (active surveillance) }\end{array}$ & $\begin{array}{l}\text { Prostate cancer-specific } \\
\text { mortality }\end{array}$ \\
\hline Oncotype DX & $\begin{array}{l}\text { Quantitative RT-PCR for } 12 \\
\text { prostate cancer-related genes and } \\
5 \text { housekeeping controls }\end{array}$ & $\begin{array}{l}\text { Biopsy, low- to intermediate-risk } \\
\text { treated with RP }\end{array}$ & $\begin{array}{l}\text { Non-organ-confined pT3 or } \\
\text { Gleason grade } 4 \text { disease on RP }\end{array}$ \\
\hline \multirow[t]{6}{*}{ Prolaris } & \multirow{6}{*}{$\begin{array}{l}\text { Quantitative RT-PCR for } 31 \text { cell } \\
\text { cycle-related genes and } 15 \\
\text { housekeeping controls }\end{array}$} & $\begin{array}{l}\text { TURP, conservatively managed } \\
\text { (active surveillance) }\end{array}$ & $\begin{array}{l}\text { Prostate cancer-specific } \\
\text { mortality }\end{array}$ \\
\hline & & $\begin{array}{l}\text { Biopsy, conservatively managed } \\
\text { (active surveillance) }\end{array}$ & $\begin{array}{l}\text { Prostate cancer-specific } \\
\text { mortality }\end{array}$ \\
\hline & & \multirow[t]{2}{*}{ Biopsy, localized prostate cancer } & Biochemical recurrence \\
\hline & & & Metastasis \\
\hline & & $\begin{array}{l}\text { Biopsy, intermediate-risk treated } \\
\text { with RT }\end{array}$ & Biochemical failure \\
\hline & & $\begin{array}{l}\text { RP, node-negative localized } \\
\text { prostate cancer }\end{array}$ & Biochemical recurrence \\
\hline ProMark & $\begin{array}{l}\text { Multiplex immunofluorescent } \\
\text { staining of } 8 \text { proteins }\end{array}$ & Biopsy, Gleason grade $3+3$ or $3+4$ & $\begin{array}{l}\text { Non-organ-confined } \mathrm{pT} 3 \text { or } \\
\text { Gleason pattern } 4 \text { disease on } \\
\text { RP }\end{array}$ \\
\hline \multirow[t]{3}{*}{ PTEN } & \multirow[t]{3}{*}{$\begin{array}{l}\text { Fluorescence in situ hybridization } \\
\text { or IHC }\end{array}$} & $\begin{array}{l}\text { TURP, conservatively managed } \\
\text { (active surveillance) }\end{array}$ & $\begin{array}{l}\text { Prostate cancer-specific } \\
\text { mortality }\end{array}$ \\
\hline & & Biopsy, Gleason grade $3+3$ & $\begin{array}{l}\text { Upgrading to Gleason pattern } \\
4 \text { on RP }\end{array}$ \\
\hline & & RP, high-risk localized disease & Biochemical recurrence \\
\hline
\end{tabular}

Abbreviations: FFPE, formalin-fixed, paraffin-embedded; IHC, immunohistochemistry; RP, radical prostatomy; RT, radiation therapy; RT-PCR, reverse transcription polymerase chain reaction; TURP, transurethral resection of the prostate.

Adapted from Mohler JL, Armstrong AJ, Bahnson RR, et al. NCCN Clinical Practice Guidelines in Oncology: Prostate Cancer. Version 2.2016. Available at NCCN.org; MS-40. To view the most recent version of these guidelines, visit NCCN.org.

$39 \%$ and $49 \%$ of men, respectively, into lower risk categories; metastasis-free survival rates were $97 \%$ and $96 \%$, respectively. ${ }^{12}$

"These tests have prognostic value and may be useful for shared decision-making, but genomic signatures that are predictive for treatment response will ultimately have more value." These signatures are starting to be reported. For instance, a manuscript currently submitted and in review by Zhao et al attempts to define a genomic signature to predict response to radiation. A high score signals that men treated with radiation will have a decreased rate of metastasis. The score itself, however, is not predictive of decreased metastasis in men not undergoing radiation. "If validated, this predictive test could help identify men who would have the most to gain from radiation therapy," he added.

\section{Clinical Practice}

Looking at NCCN risk categories, for men who fulfill very low-risk criteria and are older than 65 years, 


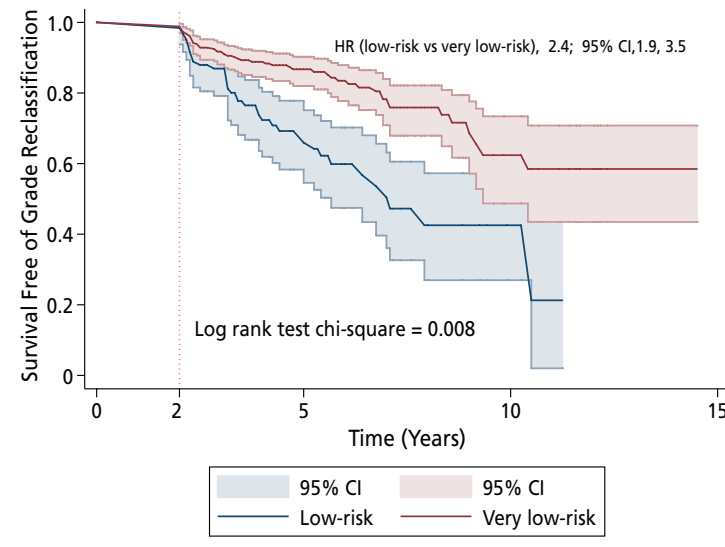

- Most testing will be confirmatory (noninformative) - Limited published data from - Cost considerations

active surveillance cohorts

Figure 1. Grade reclassification during active surveillance of men at very low risk and low risk.

From Alam R, Carter HB, Landis $\mathrm{P}$, et al. Conditional probability of reclassification in an active surveillance program of prostate cancer. J Urol 2015;193:1950-1955.

Dr. Ross stated that "no additional molecular tests are indicated." With careful follow-up and serial biopsies, virtually no prostate cancer-specific deaths have been reported in very low-risk disease. "An interesting concept is whether using a molecular test can allow for deferral of frequent biopsies in this very low-risk group. This has not been tested longitudinally," Dr. Ross noted.

The situation is different for low-risk prostate cancer. The data for active surveillance of men with NCCN low-risk disease are limited compared with very low-risk disease, and these men are at significantly higher risk of grade reclassification during surveillance (Figure 1). ${ }^{13}$ Although most molecular tests will be confirmatory in men with NCCN low-risk disease, some men in this risk category may benefit from testing. "The rate of higher grade classification is significantly higher on biopsy. PTEN-ERG tests and other tests might provide added information in the low-risk group. Some of these men might need treatment to prevent progression of disease and metastasis," Dr. Ross commented.

For men with intermediate- or high-risk disease who need primary treatment, available tests currently do not aid in the decision between radical prostatectomy and radiation therapy as primary therapy.
Molecular tests should be put in the context of current practice, where multiparametric MRI, fusion biopsy, and nomograms for treatment decisions are being used.

The largest impact of molecular tests will be in the areas with the greatest treatment-decision uncertainty regarding primary therapy for intermediate- and high-risk disease: radical prostatectomy versus radiation therapy; intensity of radiation therapy; whether to add androgen deprivation therapy to radiation therapy; and early use of docetaxel. "Predictive biomarkers would be informative in this setting and would be a large advancement," Dr. Ross concluded.

\section{References}

1. Cuzick J, Swanson GP, Fisher G, et al. Prognostic value of an FRNA expression signature derived from cell cycle proliferation genes in patients with prostate cancer. Lancet Oncol 2011:12:21-19.

2. Cooperberg MR, Simko JP, Cowan JE, et al. Validation of a cell-cycle progression gene panel to improve risk stratification in a contemporary prostatectomy cohort. J Clin Oncol 2013;31:1428-1434.

3. Bishoff JT, Freedland SJ, Gerber L, et al. Prognostic utility of the cell cycle progression score generated from biopsy in men treated with prostatectomy. J Urol 2014;192:409-414.

4. Freedland SJ, Gerber L, Reid J, et al. Prognostic utility of cell cycle progression score in men with prostate cancer after primary external beam radiation. Int J Radiat Oncol Biol Phys 2013;86:848-853.

5. Cuzick J, Stone S, Fisher G, et al. Validation of an RNA cell cycle progression score for predicting death from prostate cancer in conservatively managed needle biopsy cohort. Br J Cancer 2015;113:382389.

6. Brand TC, Zhang N, Crager MR, et al. Patient-specific meta-analysis of 2 clinical validation studies to predict pathologic outcomes in prostate cancer using the 17-gene Genomic Prostate Score. Urology 2016;89:6975.

7. Blume-Jensen P, Berman DM, Rimm DL, et al. Development and clinical validation of an in situ biopsy-based multimarker assay for risk stratification in prostate cancer. Clin Cancer Res 2015;21:2591-2600.

8. Karnes RJ, Bergstrath EJ, Davicioni E, et al. Validation of a genomic classifier that predicts metastasis following radical prostatectomy in an at risk patient population. J Urol 2013;190:2047-2053.

9. Ross AE, Johnson MH, Yousefi K, et al. Tissue-based genomics augments post-prostatectomy risk stratification in a natural history cohort of intermediate- and high-risk men. Eur Urol 2016;69:157-165.

10. Klein EA, Yousefi $K$, Haddad Z, et al. A genomic classifier improves prediction of metastatic disease within 5 years after surgery in nodenegative high-risk prostate cancer patients managed by radical prostatectomy without adjuvant therapy. Eur Urol 2015;67:778-786.

11. Cooperberg MR, Davicioni $E$, Crisan $A$, et al. Combined value of validated clinical and genomic risk stratification tools for predicting prostate cancer mortality in a high-risk prostatectomy cohort. Eur Urol 2015;67:326-333.

12. Freedland SJ, Choeurng V, Howard L, et al. Utilization of a genomic classifier for prediction of metastasis following salvage radiation therapy after radical prostatectomy [published online ahead of print January 21, 2016]. Eur Urol, doi: 10.1016.j.eururo.2016.01.008.

13. Alam R, Carter HB, Landis $P$, et al. Conditional probability of reclassification in an active surveillance program of prostate cancer. J Urol 2015;193:1950-1955. 